\title{
O CONCEITO DE PACIÊNCIA EM KIERKEGAARD
}

\author{
[THE CONCEPT OF PATIENCE IN KIERKEGAARD]
}

Ramon Bolivar Cavalcanti Germano * Universidade Estadual da Paraíba, Brasil

\begin{abstract}
Resumo: Nosso objetivo neste artigo é analisar o conceito de paciência em Kierkegaard assim como apresentado nos discursos edificantes Adquirir a sua alma na paciência (1843) e Preservar a sua alma na paciência (1844). Mostramos como o conceito de paciência envolve uma compreensão peculiar do Eu (simesmo, Selv) e como se articula aí uma relação entre a paciência e o eterno. Como isso abrimos uma perspectiva de leitura mais ampla que insere o debate específico sobre a paciência em uma discussão mais geral acerca do conceito de transcendência. Mostramos o vínculo que existe entre a paciência, como uma experiência humana de autotranscendência, e o eterno, como transcendência absoluta. $\mathrm{O} E u$ que se adquire e se preserva na paciência está posto em uma situação de autotranscendência, ou seja, é retirado de sua posição autocentrada e liberado de seu apego a si mesmo e ao mundo. Em outros termos, o que a paciência nos revela é que, a conformação do si-mesmo à sua própria medida depende, antes de tudo, de um deslocamento que transtorna a mundividência autofixada do Ego.
\end{abstract}

Palavras-chave: Si-mesmo. Paciência.

Abstract: Our aim in this article is to analyze the concept of patience in Kierkegaard as presented in the Upbuilding Discourses Acquire your soul in patience (1843) and Preserve your soul in patience (1844). We show how the concept of patience involves a peculiar understanding of the Self (Selv) and how a relationship between patience and the eternal is articulated there. In this way, we open a broader reading perspective that inserts the specific debate about patience in a more general discussion about the concept of transcendence. We show the link that exists between patience, as a human experience of self-transcendence, and the eternal, as absolute transcendence. The self that is acquired and preserved in patience is placed in a situation of self-transcendence, that is, it is removed from its self-centered position and freed from its attachment to itself and the world. In other words, what patience reveals to us is that the conformity of the self to its own measure depends, above all, on a displacement that surpasses the self-fixed worldview of the Ego.

KeYwords: Self. Patience. World. Mundo. Transcendência. Autotranscendência.

\section{INTRODUÇÃo}

Já é bastante conhecido o conteúdo da proposição que abre um dos textos capitais de Kierkegaard, a saber, $A$ Doença para a Morte (1849), assinado pelo pseudônimo Anti-Climacus. Ali Kierkegaard formula de maneira sumária uma

* Professor do Departamento de Filosofia da Universidade Estadual da Paraíba (UEPB). Doutor em Filosofia pelo Programa integrado de pós-graduação UFPB-UFPE-UFRN. Membro da Sociedade Brasileira de Estudos de Kierkegaard (SOBRESKI). E-mail: bolivargermano@gmail.com 
compreensão do ser humano - a rigor, do Selv, do si-mesmo - que será decisiva não apenas para a compreensão global de seu pensamento, mas sobretudo para a sua recepção e apropriação contemporânea. Segundo a formulação concisa de AntiClimacus, ser si-mesmo é ser uma relação que se relaciona consigo mesma; não simplesmente uma relação, mas o relacionar-se da relação consigo mesma (Cf. SKS 11-SD, p.129). Dito assim, sem mais nem menos, a fórmula poderá ser interpretada como uma definição arbitrária, como se tivesse sido "catada" de maneira rapsódica. Não é o caso. Voltando-se para o ser humano concreto como fenômeno, Anti-Climacus encontra no que se mostra uma síntese antitética: "O homem é uma síntese de infinitude e finitude, do temporal e do eterno, de liberdade e necessidade, em suma, uma síntese" (KIEKEGAARD, 2008b, p.33, tradução nossa, SKS 11-SD, p.129) ${ }^{1}$. Como uma síntese (simples relação de dois termos), o ser humano é já uma relação enquanto terceiro termo, embora ainda não seja um si-mesmo. Na síntese, os termos antitéticos são postos um em função do outro ou, com mais precisão, tornam-se momentos de uma unidade negativa na qual cada um é o que é na relação para com o outro. Este "outro" assume sempre a qualidade de negativo relativamente ao primeiro. Compreendida assim, enquanto um terceiro termo como unidade negativa, a relação ainda não configura o simesmo. "Pelo contrário, se a relação se relaciona consigo mesma, então esta relação é o terceiro positivo, e isto é o si-mesmo" (KIEKEGAARD, 2008b, p.33, tradução nossa, SKS 11-SD, p.129). Agora o si-mesmo é de fato, positivamente, uma relação que se relaciona consigo mesma. Esta formulação está longe de ser óbvia, apesar de sua concisão. Com efeito, esse movimento redobrado faz com que a relação que o si-mesmo é só seja tal na medida de sua relação para consigo mesma. Com outras palavras, a definição de Anti-Climacus quer acentuar a ideia de um movimento intrínseco e incessante no interior do homem. Ser-si-mesmo, neste caso, é relacionar-se consigo mesmo; mas para relacionar-me comigo mesmo, preciso já ser um si-mesmo (uma relação que se relaciona consigo mesma). A circularidade da definição é proposital. $\mathrm{O}$ que o si-mesmo "é" não está simplesmente determinado como o "ser" de uma pedra, de uma árvore ou de um animal. Para o homem, ser é tornar-se em, é vir a ser o que se é, é adquirir-se a si mesmo.

Ora, a ideia de aquisição de si mesmo ou, se preferirmos, a ideia do "tornar-se naquilo que já se é" acompanha a produção autoral de Kierkegaard desde o princípio. $\mathrm{O}$ que $A$ Doença para a Morte apresenta em temos particularmente formais é o resultado de um esforço de pensamento que remente no mínimo ao idos de 1843, ano de publicação das primeiras séries de Discursos Edificantes. Ali, a compreensão do simesmo como uma relação que se relaciona consigo mesma já está prefigurada de maneira essencial, sobretudo nos dois discursos dedicados ao conceito de paciência ${ }^{2}$. $\mathrm{O}$ objetivo deste trabalho é a apresentação - mais panorâmica do que gostaríamos - de alguns traços que julgamos cruciais para a compreensão do conceito de paciência em Kierkegaard $^{3}$. Em língua portuguesa, o tema foi estudado no pormenor pelos professores N. Ferro e M. Jorge de Carvalho quando da tradução e publicação de Adquirir a sua alma na paciência. Importa registrar que a primeira parte deste artigo deve muito à leitura do estudo de Ferro e de Carvalho e tenta contribuir, de modo próprio, para o debate suscitado ali. Na segunda parte queremos principalmente indicar, ainda que de maneira tangencial, o teor da preocupação que motivou este estudo, qual seja: pensar a relação que se estabelece entre a paciência e o eterno. Com isso, podemos abrir uma perspectiva de leitura mais ampla (conferir nossa conclusão), que insere o debate específico sobre a paciência em uma discussão mais geral acerca do conceito de transcendência, tema que tem ocupado nossas pesquisas atuais. 


\section{ADQUIRIR A SI MESMO NA PACIÊNCIA}

No discurso Adquirir a sua alma na paciência (1843) a concepção do si-mesmo como a autocontradição do temporal e do eterno - e mais ainda, como uma relação que se relaciona consigo mesma - é associada à necessidade de autoaquisição ou de apropriação de si mesmo. Que esta aquisição só se poderá realizar na paciência, é o que o discurso põe em jogo e o que nós gostaríamos de destacar em um primeiro momento. Senão vejamos.

$\mathrm{O}$ referido discurso abre com um anacoluto poético que cria a atmosfera desejada para a leitura: "O pássaro rico vem a silvar, vem com alvoroço. O pássaro pobre - e a paciência é um pássaro pobre que não vem com ares e gestos exteriores, mas como uma suave brisa e um incorruptível ser de espírito tranquilo" (KIERKEGAARD, 2007, p. 9, SKS 5-4T43, p. 159). Como um pássaro pobre, a paciência não tem atrativos nem traços que fascinam; não promete grandes feitos nem é capaz de ações magníficas; não se apressa nem se inquieta com o passo lento dos dias nem se alvoroça com a celeridade das horas. E é justamente este "pássaro pobre", a paciência, que assume o lugar central na passagem que motiva o discurso. Nela se lê.

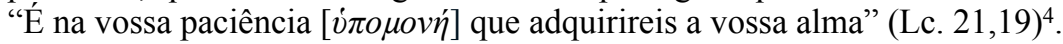

Trata-se, para Kierkegaard, de um tipo insólito de aquisição. Alma, aqui, está longe de significar simplesmente aquilo que "anima" o corpo ou ainda a substância etérea do homem, uma aura que o deixaria depois da morte, e assim por diante. Alma designa aqui o próprio ser do homem, é sinônimo de si-mesmo ( $\mathrm{Selv}$ ). Por isso adquirir a sua alma significa, antes de mais, adquirir a si mesmo - uma evidente contradição! Se um homem possui a si-mesmo, não necessita adquirir a si mesmo, e se não possui a si mesmo, como poderá adquirir-se, já que o seu si-mesmo é a condição necessária de toda aquisição? Pergunta Kierkegaard: "haverá uma tal posse que signifique precisamente a condição de adquirir a mesma posse?" (KIERKEGAARD, 2007, p. 15, SKS 5-4T43, p. 162). Sua resposta é assertiva: "No sentido exterior, não há tal posse" (KIERKEGAARD, 2007, p. 15, SKS 5-4T43, p. 162).

Toda aquisição que é aquisição de algo outro que não si mesmo é exterior ao simesmo. Isso significa, nos termos de Kierkegaard, que não se pode adquirir e possuir a mesma coisa [exterior] ao mesmo tempo. O caráter meramente temporal da exterioridade torna impossível a aquisição e a posse simultânea do exterior. "A temporalidade não compreende, nem como enigma, nem como resolução do enigma, uma auto-contradição como a que haveria de afirmar as duas partes" (KIERKEGAARD, 2007, p. 16, SKS 5-4T43, p. 163). Assim, o si-mesmo não pode ser adquirido como se fosse um objeto exterior, dado que a exterioridade é determinada pela temporalidade. Aquilo que se possui e adquire simultaneamente precisa ser e não ser ao mesmo tempo. Precisa não ser para poder ser adquirido, e precisa já ser porque o que se adquire não é nada mais do que si mesmo - a condição necessária de toda aquisição. Se essa contradição (ser $e$ não ser) não pode ser compreendida meramente no tempo - para o qual vale apenas a dialética de Hamlet, "ser ou não ser" - tampouco poderá ser assumida pelo eterno, pois o eterno simplesmente "é" - é a plena posse de si mesmo. No tempo ou possuo algo que, enquanto posse, não pode ser adquirido, ou posso adquirir algo que só depois da aquisição poderá ser possuído. Adquirir e possuir a mesma coisa ao mesmo tempo, isso o tempo não admite. Por outro lado, essa autocontradição não pode ser uma determinação da eternidade, já que o eterno apenas "é" não pode ser adquirido nem tampouco perdido. Onde então se pode encontrar uma tal posse auto-contraditória? "É no interior", diz Kierkegaard, "que esta auto-contradição tem de ser procurada. Mas o interior é, na sua expressão mais geral: a alma" 
(KIERKEGAARD, 2007, p. 16, SKS 5-4T43, p. 163). E completa:

A alma é, assim, a auto-contradição do temporal e do eterno e, portanto, aqui pode possuir-se e adquirir-se a mesma coisa ao mesmo tempo. Mais ainda: se a alma é esta contradição, ela só pode ser possuída no modo de ser adquirida e adquirida no modo de ser possuída (KIERKEGAARD, 2007, p. 16, SKS 5-4T43, p. 163).

A evidente contradição indica a "estrutura" heterogênea do sujeito. Ser si mesmo é, neste caso, estar num tempo que é tempo em relação ao eterno e, igualmente, ser no eterno que é eterno em relação ao tempo. Não que haja de um lado um eterno e do outro o tempo. O que caracteriza o ser humano é justamente a intrínseca e paradoxal unidade dos termos heterogêneos. Sobre isso N. Ferro propõe a seguinte elucidação:

[...] se se focar e procurar discernir a determinação que conforma a existência humana (aquilo que faz o sujeito humano enquanto tal), verifica-se que essa determinação não só não é simples, mas caracteriza-se, além disso, pelo fato de cada um dos momentos de sentido que lhe inerem e que a moldam estar acompanhado de algo que se lhe opõe - com que está em conflito. De tal modo que todo e qualquer momento de determinação constitutivo do humano está contagiado pelo seu oposto, intrinsecamente desvirtuado ou posto em causa por ele, envolvido num inevitável conflito com ele 5 .

A “alma”, o si mesmo, é propriamente este conflito, um constante estar posto em causa que exige a reiterada "resolução" do conflito - uma resolução que nunca cessa de resolver-se e que não encontra sossego, mas paixão. Por isso o si-mesmo só pode ser possuído no modo de ser adquirido e adquirido no modo de ser possuído. Não há aqui uma posse que não seja ao mesmo tempo uma aquisição, e vice-versa. Por isso, ser simesmo é ao mesmo tempo possuir e não possuir o mesmo, adquirir e não adquirir o mesmo. A situação crítica é evidente:

E não é angustiante entrar por esse caminho onde bem depressa e a cada instante se vê a meta, mas nunca se vê a meta alcançada - ao contrário do que sucede com o caminhante, que chega à meta, e com aquele que carrega o fardo, que chega ao seu destino? Caminho onde, por assim dizer, nunca se sai do sítio - [...] Caminho onde, por assim dizer, nunca se adquire nada: nem alcançar a meta, nem descarregar o fardo [...] - antes se adquire apenas a si mesmo (KIERKEGAARD, 2007, p. 13-14, SKS 5-4T43, p. 161-162).

Esta tarefa resignada de adquirir apenas a si mesmo é, portanto, um constante avançar rumo a uma meta que está igualmente próxima e distante. Haverá então um fim que assume sempre para si a forma de começo. E quando tudo parece conquistado, quando a meta se aproxima e o horizonte se encurta anunciando o despontar do fim e a conquista da meta - aí finalmente se está mais uma vez no início. Esta aquisição não poderá jamais confundir-se com a aquisição de coisas exteriores. $\mathrm{O}$ que se adquire - e portanto que depende de uma atividade do homem - é justamente aquilo que ele passivamente já é. O humano nada cria na aquisição de si mesmo, tampouco realiza uma forma de ser do seu próprio capricho ou uma relação com a vida do seu próprio gosto. Este paradoxo, sustentado na estrutura heterogênea do si-mesmo, indica uma situação peculiar: ser si-mesmo - uma relação que se relaciona consigo mesma - é poder e ter de eleger aquilo que já se é. Inversamente, é ser capaz de polemizar consigo mesmo num modo de ser que não se auto-adquire ou que não quer apropriar-se de si mesmo. Quer dizer que ser-si-mesmo é estar posto na necessidade da identidade consigo mesmo e, ao mesmo tempo, na possibilidade da diferença. Quer dizer que no 
humano a necessidade que força é sempre posta em causa por uma liberdade que libera. Daí que o humano possa falhar na aquisição de si mesmo - diria Anti-Climacus: possa desesperar.

Há então um aspecto decisivo que se pode vislumbrar aqui. A “alma” de que fala o discurso está constituída segundo uma indigência originária que indica, na forma de uma exigência, a necessidade de aquisição. Por aquisição entende-se basicamente aquilo que sobrevém, como um "acréscimo", ao ponto originário de partida. A aquisição promove aquilo que, de partida, está simplesmente posto. Isso vale para as formas mais gerais de aquisição. No caso em questão, contudo, entende-se por aquisição algo mais elementar. Em se tratando da vida humana, a aquisição desta própria vida torna-se uma necessidade auto imposta, quer dizer: a forma de ser do humano implica sempre numa falta que precisa ser "suprida" na aquisição. Sobre isso escreve Ferro: "Numa palavra, a vida humana está constituída de tal forma que isso mesmo que de cada vez já é envolve um imperativo de aquisição"6. Em outros termos: ser humano é a cada vez ser na precisão e no ensejo da aquisição. Mas não de qualquer aquisição, e aqui está o traço distintivo do discurso. O que há de adquirir-se não é algo que, a rigor, promova um incremento, mas justamente aquilo que já se é, a sua própria alma. Mas a "alma" é aquilo que sempre já se dá como ensejo de aquisição, de modo que o que se há de adquirir é, a cada vez, a estrutura mesma que reclama aquisição.

Ora, que é essa indigência da alma? Na indi-gência algo falta desde dentro (indu; egeo). Não é uma falta do exterior, daquilo de que todo ser vivo precisa para viver. Pelo contrário, na indigência há um tipo de privação interior, algo que falta desde a raiz (desde a alma). Não se trata de "carência de pão", mas justamente de uma "fome" que o "pão" já não sacia. Esta indigência da alma não se confunde com a penúria material ou com a ausência das condições que garantiriam a vida. Nela, persiste a fome ainda que se trague o mundo inteiro! Pois o que aqui se entende por "indigência da alma" corresponde justamente ao cerne "vazio" do homem, isto é, à dimensão originária do ser humano que se revela sempre como precisão de aquisição, numa palavras, como pobreza ${ }^{7}$. De sorte que o núcleo constitutivo do homem não se dá sob a marca de uma simples determinação (natureza, essência) como nos demais entes. Ser homem é estar posto na precisão de sempre ter de adquirir aquilo que viabilize [ontologicamente] a sua própria vida. Não que tenha de adquirir as condições básicas de sua subsistência - isso todos os serem vivos precisam fazer -, mas que tenha de adquirir o próprio sentido de sua existência, isto é, o porquê que viabiliza o seu subsistir. É este sentido que falta desde a raiz, mas não segundo uma acepção banal de "falta". Com efeito, no sentido comum, dizemos que uma falta é sempre falta disto ou daquilo, quer dizer, de algo determinado. Ou se tem falta de alimento, ou de paz, ou de alegria, ou de amizade, ou de solidão - e assim por diante. Não é este o sentido de "falta" aqui em causa. A indigência da alma funda-se numa falta totalmente indeterminada, isto é, numa carência cujo objeto que poderá supri-la é, propriamente, nada. Com outras palavras, o sentido que falta e que precisa ser adquirido é, bem entendido, o sentido da própria falta. Algo falta, mas justamente algo que não sou capaz de apreender ou determinar e que, como tal, não é rigorosamente "algo", é antes coisa-nenhuma. Nisso está a fundura abissal daquela indigência: em que a falta penetra tão fundo nas raízes que coisa alguma lhe pode suprir.

Se é assim, não há coisas, não há entes, não há mundo que chegue. Persistirá a sede que não se sacia com o fel das coisas ou com a esponja avinagrada do mundo. Pois assim como para o sedento tudo que não lhe sacia a sede adquire a qualidade de vinagre, assim também para a sede da alma não há mundo que chegue - avinagra. Ora, na indigência da alma não lhe falta mundo, lhe falta "nada"! E precisamente aí reside a 
tarefa da aquisição - em ser capaz de "nada" adquirir para além de si mesma.

Significa que a indigência da alma não tem requisitos? Quer dizer que a indigência é sem forma e sem reivindicação? Que o que falta não faz qualquer reclamação de suprimento e que não requer acudimento? Não é assim que a questão está posta no discurso. Há na verdade uma profunda requisição da alma indigente, um modo de reivindicar que se afina com a "dimensão de um nada total" 8 e que, portanto, requer "algo" que supra essa falta, ainda que esse "algo" seja, propriamente, da dimensão desse "nada total". E sendo essa requisição da dimensão de um nada total, não poderá ser acudida pelo âmbito do já preenchido e do já dado a que se poderá chamar, junto com Kierkegaard, de mundo. Por isso não há mundo que chegue, porque o nada originário é tal que não se pode saciar ontologicamente com as coisas finitas que constituem o mundo. Há que se dizer: nada lhe sacia.

Há, no entanto, uma peculiaridade que se deixa transparecer no texto de Kierkegaard. A indigência que caracteriza o si-mesmo e que o acompanha desde a sua raiz mais profunda encontra-se sempre já saciada de alguma forma, isto é, posta sob uma dada determinação de partida. Quer dizer que cada homem já se acha engolfado num determinado padrão de sentido da existência que lhe permite agir e relacionar-se com a vida e com as coisas. Trata-se de uma determinação de sentido sempre já prévia na qual nos encontramos e que orienta nossa relação com os entes e com a vida. É justamente esse "sistema de sentido" que Kierkegaard quer denotar com a palavra mundo. O mundo é um tipo de solução assente que responde imediatamente ao apelo de sentido da vida propondo-lhe um rumo ou uma meta que faz calar, por assim dizer, o pathos da alma indigente. O mundo é o meio que adquire um caráter intrínseco de naturalidade na medida em que se impõe como um sistema resolutivo no interior do qual a vida da pessoa se dá:

[...] a instauração desta esfera de sentido como "meio" em que o sujeito se move não resulta de nenhum contato original com esse sentido, não provém de um efetivo confronto com aquilo em que consiste, antes se produz de tal modo que sempre já se está com isso a vigorar, se assim se pode dizer, a jusante da sua instauração e sob o seu efeito. ${ }^{9}$

Equivale a dizer que o sujeito humano se descobre sempre já no mundo, está posto sempre já numa evidência de sentido previamente dada. Estar à jusante do mundo, neste caso, implica em "ser levado" pela vazante do sentido sempre já posto. A viabilidade da vida do sujeito passará então a depender justamente da manutenção do "seu" mundo. A relação de profunda dependência do mundo se revela então óbvia. Se a minha vida movimenta-se desde o sentido assente dado pelo mundo, então o "meu" mundo me possui. Por isso Kierkegaard diz claramente que se o homem "possui o mundo de tal forma que a perda dele pode diminuir a sua propriedade, então ele é possuído pelo mundo" (KIEKEGAARD, 2007, p. 18, SKS 5-4T43, p. 164). Ser possuído pelo mundo é estar sempre a serviço da execução daquele sistema de sentido que orienta minha relação com os entes e com a vida em geral. Quer dizer: o mundo, cuja função seria a de viabilizar a minha vida, agora está coligado a mim de tal maneira que eu preciso dar a minha vida para viabilizar o meu mundo. Nisso, adquiro uma medida cujo cânon é o mundo e não o meu próprio Selv. Em outras palavras, o mundo me possui na medida em que se torna minha fonte de constituição ontológica. Eu me torno, por assim dizer, um ente meramente mundano, isto é, medido com o metro do mundo.

Aqui reside o ponto crítico dessa relação de subordinação com o mundo. Coligirse com o mundo, com efeito, implica em medir-se desde a medida do mundo e, 
portanto, renunciar à sua própria medida. Ora, mas no discurso em questão essa medida "apropriada" não é nada de determinado. E é justamente isto que designamos como indigência da alma. Quer dizer que ser si-mesmo é não poder afinal medir-se com um metro fixo e finito tal qual o mundo. Estar na indigência é precisamente não poder resolver-se ontologicamente (saciar-se) apenas com o mundo. Quando então se obstina em permanecer medindo-se com o metro do mundo, o Selv ao mesmo tempo renuncia a si mesmo, quer dizer, passa a constituir a sua vida sob uma forma de negação daquilo que ele propriamente é. Esta é uma negação de sua própria indigência originária, de modo que deixar-se possuir pelo mundo é, no fundo, uma tentativa desesperada de anular a carência essencial que caracteriza o si-mesmo. É uma "tentativa desesperada" porque, como temos dito, não há mundo que chegue. Quanto mais o si-mesmo se apega ou adere ao mundo, mais a sua única necessidade é a de desvencilhar-se do mundo para poder vivenciar profunda e transparentemente o estado ab-soluto de sua indigência.

Adquirir a sua alma, neste caso, é ser capaz de subtraí-la do mundo para trazê-la de volta para a sua justa medida. A dificuldade, contudo, está justamente no cerne "vazio" dessa medida. Quer dizer que quando abre mão da posse do mundo, o simesmo não encontra consolo em outro mundo, isto é, em outro sistema fixo de sentido que lhe imponha sua medida. Ao desvencilhar-se do mundo o si-mesmo não se encontra com "algo" posto à sua disposição e para o qual ele mesmo está à disposição, antes se encontra consigo mesmo na forma originária da indigência. Não há aí um "algo" a que se apegar, uma coisa, um mundo, mas um estado de aberto, uma possibilidade. E é aqui - quando descobre que o mundo não lhe basta e que no âmago subjaz uma profunda indigência - é aqui que o sujeito adquire a sua alma na paciência.

$\mathrm{Na}$ paciência "algo" se cala, há um silêncio de entes ou um silêncio de mundo que cria a possibilidade de auscultação de si mesmo. Reina uma calmaria de fím de tarde, quando o fervor do meio dia se aplaca e dá lugar a um mormaço cálido e calado. A calma da paciência é como o acender-se da chama interior do si-mesmo. Algo ali começa a animar-se, a acalorar-se, isto é, a acalmar-se. Não há qualquer desmesura, nada de afã, pressa nenhuma. Há uma chama interior que queima na mais justa medida, alheia a qualquer hybris - expectante, mas sem ânsia; esperançosa, mas sem ilusões. A vela é o símbolo da paciência calma: queima serena e constantemente e, a depender do seu tamanho, pode queimar por dias, semanas, meses... Se ardesse desmedidamente, consumiria toda a cera de uma só vez e cessaria. Mas não, seu ardor é calmo, é absolutamente comedido. Assim com a vela da paciência. Sua espera ardente é plenamente comedida com a indigência ontológica da alma. Não anseia desesperadamente por sossego, por cessação, por resolução mundana - quer apenas arder e continuar assim, calmamente viva, como se aquela calmaria pudesse perdurar por toda uma eternidade! Por isso a paciência não quer outra coisa senão a própria paciência, não espera a glória, antes encontra a glória na espera. É o que diz Campos quando escreve: "Na espera dessa paciência, a conquista maior não é a glória obtida após a realização do percurso de um dado caminho, porque o caminhar da paciência é a própria glória" (CAMPOS, 2017, p, 227, grifo do autor). Na paciência não conquisto o sossego, a glória do mundo, mas a calma da alma. Aí apreendi a minha alma tal como ela é, a saber: como aquilo que "não é, antes passa a ser" (KIERKEGAARD, 2007, p. 29, SKS 5-4T43, p. 170) - passa a ser paciência. Assim como o burrinho pedrês de Rosa venceu a bruta travessia na paciência, "sem afã, à voga surda, amigo da água"10, assim também o si-mesmo pôde encontrar-se consigo mesmo apenas quando, sem afã, adquiriu-se a si mesmo na paciência.

Apenas a paciência é capaz de acudir ao grito de socorro da alma indigente porque possui a qualidade excepcional de ser uma afluente do eterno. Nela não 
conquisto coisas, não apreendo entes, não adiro a um mundo, mas adquiro a mim mesmo numa relação franca para com minha própria precariedade ontológica. A paciência não ilude, pois não oferece o descanso inerte da indolência existencial, mas o descanso dinâmico da espera continuada, do aguardar que não visa à coisa, mas a si mesmo, uma espera na qual "não é preciso chegar para sempre chegar" (CAMPOS, 2017, p. 228). Por isso a paciência se torna uma justa medida, um metro digno da medida do si-mesmo. Dizíamos, com efeito, que a indigência do si-mesmo funda-se numa falta totalmente indeterminada, de modo que o sentido que falta e que precisa ser adquirido é o sentido da própria falta. Algo falta, mas justamente algo que, a rigor, não é "algo". Ora, a paciência está justamente na afinação com aquela já mencionada "dimensão de um nada total" porque o que ela suscita como alimento para a indigência da alma não é nada que esteja "aí", seja isto um ente, uma coisa ou todo um mundo. $\mathrm{O}$ que se adquire na paciência é, pelo contrário, o sempre possível a que Kierkegaard gosta de chamar de eterno. Isto é nada - nada de entes e nada de mundo - mas ao mesmo tempo é tudo - a plenitude do eternamente novo que se dá sempre hoje mesmo ${ }^{11}$.

Agora a paciência se afigura como aquela "pastora de almas" que realiza "a mais resignada de todas as tarefas da vida": tornar-se naquilo que já se é. Há na paciência aquela beatífica re-signação, que não é mera passividade ou padecimento, "pois a paciência é sempre tão atuante quanto padecente, e tão padecente quanto atuante" (KIERKEGAARD, 2010, p. 206, tradução nossa, SKS 5-2T4, p. 199-200) ${ }^{12}$. É na paciência que o selo do mundo é removido para dar lugar a uma relação transparente para consigo mesmo e para com a vida. Na re-signação da paciência, já não há mais o desejo desmedido de ser outro que não si mesmo. Já não se quer ser, impacientemente, algo de maior do que se é. Pois na paciência eu mesmo descobri-me como paciência, como o ente singular e extraordinário que só pode "realizar" o seu ser na forma da eterna paciência - do contrário renuncia a si mesmo.

\section{Preservar a Si Mesmo NA PACIÊNCIA}

Adquirir a sua alma na paciência significa, portanto, estar sempre e renovadamente a adquiri-la, quer dizer, estar posto numa relação de aquisição pela qual aquilo que se adquire é justamente aquilo que imediata e simultaneamente requer a aquisição. Com efeito, a indigência $d a$ alma de que falávamos se mostrou também como uma indigência de alma. $\mathrm{O}$ que isso quer dizer? Que a aquisição de si mesmo não significa apenas um modo de adquirir algo, mas antes um modo de descobrir afinal o que se tem de adquirir - pois é justamente essa falta que subjaz desde a raiz. A paciência, neste caso, é a "categoria" privilegiada que permite ao si-mesmo entabular uma relação franca para consigo mesmo, uma vez que apenas na e pela paciência estou a descobrir-me, a desvelar-me para mim mesmo, isto é, estou num incessante processo de autodescoberta mediante o qual tomo consciência justamente daquilo que é digno de ser adquirido.

No discurso de 1844 intitulado Preservar a sua alma na paciência, Kierkegaard retoma, segundo um óbvio nexo de continuidade, aquilo que Adquirir a sua alma na paciência havia trazido à tona. Podemos ler ali: "Um homem não adquire primeiro a sua alma e então necessita da paciência para preservá-la, antes não a adquire senão preservando-a e, por isso, a paciência é o primeiro e a paciência é o último [...]" (KIERKEGAARD, 2010, p. 197, tradução nossa, SKS 5-2T44, p. 190). Com isso, adquirir a sua alma na paciência passa a significar igualmente preservá-la, mantê-la, 
guardá-la na paciência. Kierkegaard é claro ao afirmar que não adquiro algo que então preciso preservar na paciência, mas que adquiro justamente aquilo que só se pode adquirir segundo uma preservação na paciência. De sorte que aquilo que adquiro é, numa palavra, paciência, e aquilo que então preservo é igualmente - paciência. Adquirir a sua alma na paciência é, então, preservar a paciência mesma e, nisso, preservar a sua alma. Dizer que a paciência é o primeiro e o último significa, neste caso, que o telos da aquisição é a preservação e o telos da preservação é a aquisição, de modo que a meta é a paciência, mas ao mesmo tempo a paciência é o caminho, o que significa, em suma, que o caminho é a meta.

Esta relação parece ser cara para Kierkegaard. Em se tratando do ser humano, cuja meta ou o fim não se pode reduzir à finitude de um algo, a tarefa se configura como o caminho. Quer dizer que a meta não poderá ser alcançada enquanto não a pudermos encontrar no próprio caminhar. Pois o caminhar é expressão alegórica do instante de intersecção do tempo e do eterno no homem. O tempo corre, o eterno para, mas quando ambos se tocam, o correr do tempo é refreado e o parar do eterno é movido $^{13}$. Aí se dá o caminhar. No caminhar une-se ao lapso do tempo a plenitude do eterno. Caminha-se porque o correr é pouco e o parar é demasiado. Se corro, perco o eterno, se paro, perco o tempo. Em ambos os casos estou distante de mim mesmo, isto é, do instante. Agora, a paciência é precisamente esse caminhar que não se afana com o fluxo daquilo que passa correndo (vanitas vanitatum) - isso é pouco para um existente! - nem se imobiliza com a plenitude do eterno - isso é demasiado para um existente! Segundo essa perspectiva, a paciência me põe a caminho e me faz encontrar aí, no próprio caminho, o meu telos. Ora, isso quer dizer que o meu telos está em jogo e que, como tal, precisa ser sempre e incessantemente desvelado! É esta a primeira acepção que Kierkegaard dá à expressão preservar a sua alma na paciência. Diz ele: "Preservar a sua alma na paciência, quer dizer, pela paciência assegurar-se do que é que se tem de preservar" (KIERKEGAARD, 2010, p. 197, tradução nossa, SKS 5-2T44, p. 190).

Ora, sabe-se que o que se tem de preservar é a alma, mas ao mesmo tempo está dito que a tarefa consiste em assegurar-se sobre o que é que se tem de preservar. Quer dizer que isso a que se chama "alma" não está dado para ser preservado pura e simplesmente, como uma coisa que guardo e conservo. Antes o contrário: isso que tem de ser preservado precisa justamente ser "descoberto" pela paciência. Note-se, é a paciência que realiza a tarefa, de modo que aquilo que se tem de preservar não é nada da dimensão fática como os entes, as coisas, o mundo. Tudo isso poderá ser adquirido e preservado malgrado a paciência. Não é assim com o si-mesmo. Preservá-lo na paciência significa que só na e pela paciência esse si-mesmo poderá então despontar para a relação. "Pela paciência assegurar-se do que é que se tem de preservar" significa então que aquilo que é digno do homem, aquilo mesmo que há de ser preservado, só poderá ser descoberto pela paciência. Não por uma paciência exterior que, uma vez tendo alcançado o objeto de desejo, torna-se supérflua. Pelo contrário, a paciência de que aqui se trata corresponde ou conforma-se à existência humana. Por isso, não é um simples meio para um fim, mas um "fim" em si mesmo. Tanto que a expressão insólita de Kierkegaard poderá afinal significar que aquilo que pela paciência desponta como o que tem de se preservar é, bem entendido, a própria paciência. E então mais uma vez a paciência é o primeiro e a paciência é o último.

A este ato de discernimento promovido pela paciência - que afinal discerne aquilo que é digno de ser preservado - Kierkegaard chama de deliberação [Overveielsen] (Cf. SKS 5-2T44, p. 191). É uma deliberação porque considera cuidadosamente sobre aquilo que há de ser preservado. Mas não é uma deliberação qualquer, porque aí quem delibera é a paciência. Por isso Kierkegaard saberá 
reconhecer "quão necessária é a deliberação para o homem", mas também "quão necessária é a paciência para a deliberação" (KIERKEGAARD, 2010, p. 198, tradução nossa, SKS 5-2T44, p. 191). Mais ainda, deliberação e paciência aparecem então como "essencialmente o mesmo" (Cf. SKS 5-2T44, p. 191), o que dá ao termo "deliberação" um sentido obviamente transposto ${ }^{14}$. Com efeito, na deliberação da paciência diferente de qualquer outra deliberação - não chego a uma conclusão sobre o objeto deliberado que me faça enfim deixar de deliberar; não resolvo um impasse que, depois de resolvido, torna supérflua a deliberação; não adquiro nada de extrínseco nem tampouco sou promovido mundanamente. Não, na deliberação da paciência torno-me apenas inteirado sobre mim mesmo, entro num relacionamento sincero para comigo mesmo, de modo que aquilo que adquiro é apenas a medida de meu próprio ser e de minha própria vida - nada além disso. Quer dizer que na deliberação da paciência adquiro paciência para poder preservar a mim mesmo na paciência. Com outras palavras, a paciência permite que minha relação para comigo mesmo e para com a vida esteja fundada numa consideração paciente, isto é, num modo de ser que se dá na forma de uma espera confiada (esperança), de uma entrega solta, de uma fé desprendida, de uma confiança desapegada. São modos distintos de dizer o mesmo, a saber: na paciência abre-se mão de um sistema fixo de significação de si mesmo e da vida. Quer dizer que nenhum sistema de sentido é fixado como a garantia de verdade de si mesmo, antes o contrário, a paciência afina-se com um "sentido" aberto, eterno, um "sentido" que se dá sempre nas formas privilegiadas de vivência do eterno no tempo (esperança, fé, amor, etc.). O que, neste caso, caracteriza a deliberação da paciência é que nela e a partir dela o ser humano é capaz de discernir sobre aquilo que deverá orientar a sua relação para consigo mesmo e para com a vida. Esse discernimento, contudo, resultará na profunda consciência de que aquilo que poderá assegurar o sentido de si mesmo e da vida não é, de maneira nenhuma, um conteúdo meramente finito e temporal, mais ou menos fixado. Antes o contrário: a paciência descobre que ser si-mesmo nesta vida (sem fantasias sedutoras ${ }^{15}$ ) só é possível segundo um imperativo de espera e de confiança, isto é, segundo um modo de ser que não compreende nem determina um sentido para si e para a vida, mas que crê num sentido que não provém dos desejos, anseios ou inclinações do próprio eu. Compreender, determinar, descobrir, buscar um sentido para si mesmo e para vida, tudo isso em última instância é ainda impaciência. Aquele que então preserva a sua alma na paciência o faz porque se entrega a uma perspectiva transcendente de sentido, quer dizer, a uma relação consigo mesmo e com a vida que só é capaz de "encontrar" sentido numa espera paciente, no aguardar sempre animado que nunca cessa no tempo, mas que se projeta para o eterno. Equivale a dizer que na paciência renuncia-se a toda imposição de sentido fundada no desejo, a toda forma de verdade "forte" (objetiva), a todo sentimento de "em vão" que se ressente da vida, a toda "vingança" conta si mesmo, a toda ânsia de domínio, à soberba e à concupiscência. Todas essas formas de relação - que são impaciência - caracterizam-se pela absolutização de um eu ensimesmado que, como tal, é incapaz de se abrir para o eterno que há em si. É este "eterno" que a paciência, por assim dizer, acessa. Não se trata de algo alheio ao homem, mas de sua própria "essência" transcendente que se manifesta temporalmente como dependência. A paciência abre o eterno na medida em que faz o si-mesmo entrar em contato com a dependência absoluta de seu ser lançado na vida. De sorte que o que se preserva na paciência é, já o sabemos, a própria paciência, mas isso significa igualmente: preserva-se livremente a própria dependência. Não se preserva algo que meramente se possui ou se tem, tampouco um poder sobre ou a capacidade de dominar isto ou aquilo, de ser senhor de, etc. O que se preserva na paciência é uma falta e uma precisão, uma dependência que não desespera de si mesma. Assim, a alma 
que se preserva na paciência é a alma livremente dependente. Não que se preserve na paciência para ao final tornar-se independente, mas que se preserve na paciência justamente para permanecer sempre dependente, do princípio ao fim. Nesse sentido, a paciência sustenta livremente a dependência e, nisso, protege a alma dependente de querer constituir-se segundo uma representação fantástica e desesperada de si mesma. Sejamos mais claros.

Dizer que a alma, mediante a paciência, preserva-se segundo uma livre dependência significa que apenas aí o si-mesmo é capaz de entabular uma relação autêntica para consigo mesmo. Esta autenticidade não implica no cumprimento de um destino, de uma essência ou de uma natureza, mas justamente na relação sempre reiterada e redobrada com a condição originária de transcendência (o eterno) que constitui o si-mesmo. Com outras palavras, a tarefa é tornar-se justamente naquele ser ontologicamente dependente que cada um já é de partida. Trata-se de ser capaz de viver segundo aquela indigência da alma sem desesperar dessa mesma indigência. É esta tarefa fundamental que só a paciência é capaz de "realizar". Contra ela polemiza a impaciência, o anseio desmedido de não ser aquilo que se é, de ser algo de diferente do que se é e, portanto, de não estar sempre numa situação de indigência e dependência que requer paciência. Mas aí está o ponto crítico sempre revisitado por Kierkegaard em seus textos edificantes. Na medida em que o ser humano se recusa obstinadamente a ser indigente e dependente, é exatamente aí, nesta recusa, que ele perde a si mesmo em se tornando um indigente sem socorro e um dependente sem auxílio - um ente desesperado. Inversamente, quando mediante a paciência o ser humano preservou a sua indigência e a sua dependência - pois é isso mesmo que fica preservado na paciência então aí, livremente, tornou-se um ser cumulado de auxílio e de socorro, de modo que aquela precisão que inquietava o desesperado tonou-se para ele a mais profunda fonte de alegria e gratidão.

Ora, essa dependência é a expressão viva do eterno porque é justamente "dependência do eterno", isto é, daquilo que testemunha sobre o sentido da vida da pessoa sem que ela possa reter esse testemunho na forma de uma posse, de um saber, de um conhecimento, de um desejo, de um propósito, etc., etc. Mais ainda, o testemunho de sentido não provém da subjetividade isolada pura e simplesmente ${ }^{16}$ (o que chamamos aqui livremente de eu ensimesmado), mas de uma relação subjetiva de entrega e de abandono a um "sentido" incognoscível ou insondável, isto é, um "sentido" que não é uma posição do eu, mas a sua de-posição.

\section{Conclusão}

Não poderíamos finalizar este estudo sem indicar a perspectiva que ele parece abrir para nós. O conceito de paciência, bem como as noções de fé, esperança, amor, etc., mantém-se em íntima correlação com a ideia do eterno, cuja presença recorrente nos textos de Kierkegaard é uma indicação suficiente de sua importância capital. A paciência é essencialmente uma experiência de vínculo com o eterno. Neste sentido, é uma experiência de transcendência. A menção que fizemos não apenas à indigência, mas à dependência radical do homem em relação a um "poder" que não é coisa nenhuma. Mais ainda, a menção final a uma deposição do eu frende a um "sentido" que extrapola o âmbito fixo do seu mundo - que, portanto, não pode ser um sentido dado é exatamente uma indicação do vínculo que existe aqui entre a paciência, como uma experiência humana de autotranscendência, e o eterno, como transcendência absoluta ${ }^{17}$.

Temos em mente aqui a relação entre transcendência e autotranscendência tal 
como evidenciada pelo trabalho de Merold Westphal intitulado Transcendence and selftranscendence: on God and the soul. Ali, o autor pensa a transcendência de Deus em estreita correlação com a auto-transcendência humana (Cf. WESTPHAL, 2004). Toda e qualquer experiência de transcendência, neste sentido, implica numa renúncia à posição autocentrada do si-mesmo. A nosso ver, o que Westphal entende por self-transcendence pode ser traduzido aqui como a supressão da mundividência fixa do Eu, isto é, como o esvaziamento de seu mundo e, portanto, a quebra da aderência e do domínio do mundo sobre a alma. Ora, mas é exatamente isto que a paciência promove. O self que se adquire e se preserva na paciência está posto em uma situação de self-trancendence, ou seja, em um postura de abandono de sua posição autocentrada e de liberação de seu apego a si mesmo e ao seu mundo. Em outros termos, o que a paciência nos revela é que, a conformação do si-mesmo à sua própria medida depende, antes de tudo, de um deslocamento que transtorna a mundividência autofixada do Ego. Para ser si-mesmo o homem precisa deixar de ser um Ego, sito é, um Eu em estado de autoapego e ensimesmamento. Em temos mais diretos, para adquirir-se a si mesmo o homem precisa, em certo sentido, perder-se. É isto que o conceito de paciência parece colocar em jogo. Ao fazê-lo, sugere algo mais: que esta autotrancendência não pode, de maneira nenhuma, ser uma mera atividade positiva do $\mathrm{Eu}$, uma simples escolha ou o resultado de um esforço meramente pessoal. É apenas no instante, no momento extraordinário em que o eterno toca a finitude, que a entrega de si acontece simultaneamente à conquista de si. Para mencionar outro texto de Kierkegaard, diríamos, parafraseando Johannes Climacus em Migalhas Filosóficas, que o homem não traz consigo a condição de adquirir-se na paciência. Se ele tivesse, por si mesmo, a condição, "então precisaria apenas recordar-se" (KIERKEGAARD, 2008a, p. 34). Não é o caso. A aquisição de si, na medida em que envolve uma autotranscendência, é um acontecimento que transpõe o domínio do Eu, ou seja, é um encontro com o transcendente. Por isso é fundamental pensar a paciência não como uma experiência meramente finita e temporal, como uma paciência mundana, mas exatamente como a instauração de uma presença do eterno na vida do homem, ou seja, como a experiência de uma transcendência que transpõe os limites do $E u$ ou que desloca o mundo do centro e transtorna, portanto, a mundividência autofixada do Ego.

Desta forma, mais do que uma análise pontual de um conceito específico, a meditação de Kierkegaard sobre a paciência nos convida a pensar a transcendência como o fazer-se presente de um mistério fundante, como a presença viva do eterno no tempo, de Deus na vida do homem. Que esta presença viva subverte radicalmente a ordem da mundanidade e da egoidade é o que o conceito de paciência nos faz ver em termos filosóficos. Contudo, não podemos deixar de mencionar que as meditações de Kierkegaard sobre a paciência não se limitam a um interesse filosófico, antes querem ser essencialmente edificantes. Por isso a compreensão intelectual do conceito de paciência não pode jamais ser confundida com a paciência de que fala o discurso. Em certo sentido Kierkegaard pretende que a paciência deixe de ser um conceito e passe a ser uma vida.

\section{REFERÊNCIAS}

CAMPOS, Eduardo da Silveira. O Conceito de Repetição em Kierkegaard: quando tudo se faz novo. p. 261. Tese (Doutorado em Filosofia) - Universidade Federal do Rio de Janeiro, Intituto de ciências sociais, Programa de pós-graduação em Filosofia, Rio de Janeiro, 2017.

FERRO, Nuno. Naturalmente Hipócrita: em constante referência a Kierkegaard, Lisboa: 
Editorial Aster, 2015.

GERMANO, Ramon Bolivar. O Sopro do Eterno: sobre verdade, vida e amor e S. A. Kierkegaard. p.204. Tese (Doutorado em Filosofia) - Programa de pós-graduação em Filosofia, Universidade Federal da Paraíba, João Pessoa, 2018.

HEGEL, G.W.F. Princípios da filosofia do direito. Tradução Orlando Vitorino - São Paulo: Martins Fontes, 1997.

KIERKEGAARD, Søren A. Søren Kierkegaards Skrifer (SKS, versão 1.8.1, 2014) http://sks.dk/forside/indhold.asp

KIERKEGAARD, Søren A. Discursos Edificantes. Tres Discursos para ocasiones supuestas. Tradução de Darío González. Madrid: Trotta, 2010.

KIERKEGAARD, Søren A. Migalhas Filosóficas ou um bocadinho da filosofia de Johannes Clímacus, tradução de Álvaro Luiz Montenegro Valls e Ernani Reichmann. Petrópolis: Editora Vozes, 2008a.

KIERKEGAARD, Søren A. La Enfermedad Mortal. Tradução de Demetrio Gutiérrez Rivero Madrid: Trotta, 2008b.

KIERKEGAARD, Søren A. Adquirir a sua alma na paciência. Tradução, notas e posfácio de Nuno Ferro e M. Jorge de Carvalho, Ed. Assírio \& Alvim - Lisboa, 2007.

KIERKEGAARD, Søren A. As Obras do Amor. Tradução de Álvaro Luiz M. Valls, Vozes Petrópolis, RS; Editora Universitária São Francisco - São Paulo, (Coleção Pensamento Humano), 2005.

Novo Testamento Interlinear Grego-Português. Barueri, SP: Sociedade Bíblica do Brasil, 2004.

ROBERTS, David. Kierkegaard's Analysis of Radical Evil. Continuum: London; New York, 2006.

ROSA, João Guimarães. Sagarana. Rio de Janeiro: Nova Fronteira, 2001.

WESTPHAL, Merold. Transcendence and self-transcendence: on God and the soul. Bloomington and Indianapolis: Indiana University Press (Indiana series in the philosophy of religion), 2004.

\section{Notas}

1 Optamos por padronizar nossas citações fazendo sempre referência aos Søren Kierkegaards Scrifter (SKS - Version 1.8.1, 2014). Sempre que utilizarmos traduções faremos primeiro a referência ao texto da tradução e em seguida a indicação dos SKS. Por exemplo: (KIERKEGAARD, 2013, p. X, SKS 7-AE, p. X). Sempre que a tradução for nossa faremos referência direta aos SKS. Exemplo: (SKS 7-AE, p. X, tradução nossa).

2 Os discursos são Adquirir a sua alma na paciência (KIERKEGAARD, 2007) e Preservar a sua alma na paciência (KIERKEGAARD, 2010).

3 O núcleo deste trabalho resulta de nossa pesquisa doutoral (GERMANO, 2018). O artigo que ora apresentamos, no entanto, conta com modificações cruciais que complementam a primeira formulação do tema em nossa tese.

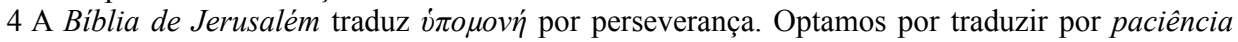
porque é nesta acepção que Kierkegaard compreende a passagem. A tradução é nossa a partir do texto disponível em Novo Testamento Interlinear Grego-Português (Cf. Referências).

5 Em nota, KIERKEGAARD, 2007, p. 96

6 Em nota, Cf. KIERKEGAARD, 2007, p. 72.

7 No discurso Adquirir à sua alma na paciência esta indigência da alma se diz "nudez".

8 Cf. nota de N. Ferro em KIERKEGAARD, 2007, p. 78.

9 Em nota, KIERKEGAARD, 2007, p. 109

10 Referimo-nos ao conto "O Burrinho Pedrês" de João Guimarães Rosa (ROSA, 2001).

11 Sobre a expressão "hoje mesmo" conferir, por exemplo, o discurso Contra a Covardia em Quatro Discursos Edificantes de 1844. SKS 5-4T44, p. 343 (Cf. em KIERKEGAARD, 2010, p. 344).

12 Em Preservar a sua alma na Paciência. 
13 É importante ressaltar, que as expressões: correr e parar, são ditas já desde o instante. Quer dizer que só posso dizer que o tempo corre porque há em mim o eterno; e só posso dizer que o eterno para desde o tempo que corre. Não há correr e parar fora da intersecção tempo-eterno. Abstraindo do instante sou incapaz de dizer algo sobre o tempo e sobre o eterno, pois fora do instante não há sequer qualquer forma de consciência, já que esta última é justamente um outro nome para o instante.

14 Sobre a ideia de discurso transposto Cf. As Obras do Amor, KIERKEGAARD, 2005, p. 240.

15 Cf. Ex. em SKS 5, 192.

16 Isso Hegel (e outros) já havia identificado como o Mal (Cf., por exemplo, os parágrafos 139 e 140 dos Princípios da Filosofia do Direito). Trata-se de um tema de importância capital para Kierkegaard e que seria digno de análise caso não nos levasse longe demais, para além dos limites deste trabalho. Mas é de suma importância chamar a atenção do leitor para esta discussão. Ao que tudo indica Kierkegaard não apenas compreende bem, mas concorda no geral com a tese de Hegel de que "É na certeza que para si existe, conhece e decide que reside a raiz comum à moralidade e ao mal" (HEGEL, 1997, p. 124). Quer dizer que Kierkegaard concorda que, bem entendido, o mal reside na subjetividade isolada, mas discorda assertivamente de que a "salvação" deva ser buscada na objetividade. Uma discussão interessante sobre esta questão fulcral pode ser encontrada em "A filosofia hegeliana como se sabe não tem ética": Kierkegaard e Hegel em tono da Ética (FERRO, 2015, p. 37-69). Sobre o problema do mal em Kierkegaard conferir o trabalho de David Roberts: Kierkegaard's Analysis of Radical Evil. Aqui se destaca a relação entre liberdade e mal - que o autor faz remeter a Kant e Schelling - com ênfase na noção final de mal como "desafio": "Na sua forma mais transparente e autodeterminada, o mal se torna uma escolha radical contra o Bem - torna-se desafio" [In its most transparent and self-determined form, evil becomes a radical choice against the Good - it becomes defiance] (ROBERTS, 2006, p. xii, tradução nossa). São questões que precisaremos deixar em aberto neste estudo.

17 Importa destacar que nos discursos estudados aqui este eterno que transcende absolutamente a esfera de atuação do Eu é, propriamente, Deus. 